\title{
'Reflections from the Margins' - Working Class White Boys, Educational Underachievement and Uncertain Futures
}

\author{
Stanley Tucker ${ }^{*}$
}

${ }^{1}$ Newman University College, School of Human Sciences, Genners Lane, Bartley Green, B32 3NT Birmingham, United Kingdom

KEYWORDS

Young people

Class

Community

Educational

underachievement

Problematization

Relationships

Curriculum

\section{ABSTRACT}

This article explores the perceptions of a group of working class white boys living in the West Midlands area of the United Kingdom. Using original data generated from a series of in-depth personal interviews matters of educational underachievement, future job prospects and ambitions are explored. In capturing the 'voice' of the young people concerned specific attention is given to how a variety of social, economic and class-based factors shape their personal and collective perceptions. It is argued that the dominant social construction of the period of youth, commonly represented through the young people's views, is underpinned by notions of marginalisation, problematisation, social exclusion and discrimination. The case is made for re-orientating the nature of school relationships and adjusting the curriculum to reflect the needs and experiences of the young people involved.

\section{Introduction}

The article presents for consideration original data gathered through a series of in-depth personal interviews with a group of white working class boys living in the West Midlands area of the United Kingdom. The intention in undertaking the research was to explore how uncertain economic and social conditions, facing many traditional white working class communities, are impacting on young males. Specific attention is given to matters of educational achievement and its potential links to issues of personal and

\footnotetext{
*Contact address: S.A.Tucker@newman.ac.uk (S. Tucker)
} 
collective identity, and future job roles and expectations. In capturing the 'voice' of the young people concerned in this way, the aim is to further advance the view of France (2004: 177) who argues that young people can act as 'competent and reliable witnesses to their own lives.' In attempting to understand the lives of others, Nieto (1999) asserts that we need to consider interrelated aspects of day-to-day existence - educational, social, cultural and economical. The article attempts to move beyond what might be considered a 'deficit' agenda when considering the lives of white working class boys to a point where a clearer understanding is gained of the issues that impact on issues of identity construction, life chances and expectations (McKnight 2006). To understand such matters it is maintained that matters of school experience, family life and peer relations have to be carefully considered - for it is within these areas that personal and collective identities are mediated (Nayak 2003).

The educational performance of working class white boys in public examinations, and school more generally, continues to be matter for concern within United Kingdom (UK) society. A recent report published by the Joseph Rowntree Foundation, a leading UK charity, reveals that this White British group are at the highest risk of remaining within the lowest 10 per cent of achievers within the British education system (Cassen and Kingdon 2007). Empirical data also points to the fact that almost half of the students, who leave school with minimal, or no, qualifications are white British males and that low achieving white boys outnumber low achieving white girls by three to two. Within post-industrial society, working class white boys are seen to underachieve throughout formal education and into employment and adulthood. In turn, they are perceived as a significant threat to 'life-long learning' policy goals of the UK government insofar as 'they are least likely to enter University and most likely to drop out' (Quinn et al. 2006: 735).

A key aim of a year-long case study (Bassey 1999), carried out in a secondary school (11-16 year olds) in the Birmingham area of the West Midlands UK, was to explore the perceptions that a group of working class white boys held about the nature of their educational experiences and how those experiences were likely to impact on future life expectations and ambitions. A group of ten young men, between the ages of fifteen and sixteen, participated in the project. Influenced by the work of Griffin (1993) 
the research project attempted to capture, through the 'voices' of the participants, the impact of common representations of the period of youth on the lives of those involved. For as Griffin argues, since the nineteenth century young working class men have variously been depicted in research, policy and service delivery terms as 'troubled', 'deficient', 'disaffected', 'delinquent', 'diseased' and 'perverted'. However, the power of these discursive representations has been so pervasive that they have assisted in shaping:

'... the contemporary Youth service, the education system, apprenticeship and training schemes, child-rearing conventions and practices, the juvenile justice system, the job market, as well as the priorities of contemporary youth research' (Griffin 1993: $11)$.

In turn, the existence of particular forms of 'problematizing' discourse has, of itself, provided 'permission' for certain groups of young people to be isolated for specific attention in terms of how they are perceived and responded to by education, health and social care agencies. 'Problematizing' discourses then, manifest themselves in a whole host of ways and in doing so serve a range of different purposes. For example, individuals and groups of young people can be effectively isolated from their peers by virtue of the levels of commentary, inspection and surveillance that are 'invited' by the state into their day-to-day existence. In exploring the lives of a specific group of young working class white boys the intention was to gauge the impact of such discursive preoccupations in terms of their impact on matters of selfidentity, esteem, educational achievement and future ambitions.

\section{Contextual literature}

Since the early 1990s there has been an increased focus on the underachievement of working class boys in the UK. This initially surfaced through governmental concern in relation to reading standards of boys at primary school level (Lindsay and Muijs 2006). However, the scope of that concern has widened considerably over time to include boys supposed refusal to embrace the learning demands of the classroom; their reluctance to 
adopt appropriate learning behaviours; their lack of personal ambition and motivation and their inability to see the value of education as a distributor of improved life chances (Younger and Warrington 2005). The influence of the power of 'problematizing' discourse can be seen in terms of both the theoretical and professional explanations provided for the way in which young working class white boys respond to the educational environments in which they find themselves. One specific representation that has gained prominence is constructed around a discourse of 'laddish' behaviour that is seen to value disruption, hedonistic activities and disrespect for school personnel (Francis 1999). As a result educational policy and practice has been refocused to reconstruct boys 'as requiring 'help' to develop into 'healthy' males' with 'the production of boys "at risk"' as being in need of a 'general "therapeutic turn" in approaches to pedagogy' (Mills, Francis and Skelton 2009: 37).

Major structural paradigm shifts pertaining to the positioning of men and women, and changes in the nature of the labour market have also had a significant impact on working class male identities (Marks 2003). These changes are said to have resulted in a distinct ambivalence among working class men towards education, which has progressed through three chronological stages over the last fifty years. These three stages are: firstly, rejection of education as a means of differentiating themselves from the higher classes, with the integration of differentialism as a central component of class culture; secondly, rejection of education on the grounds that perceptions of education are irrelevant to the future of working class males; and lastly the most recently adopted approach, rejection of education on the grounds that since education cannot guarantee a career there is little or no point to it.

It can be reasonably argued that the perceptions and attitudes of working class males towards education have been heavily influenced by the knowledge that they are unlikely to gain meaningful employment after compulsory education. The high incidence of graduates in low paid jobs has further compounded this perception (Marks 2003). The significant decline in the availability of manual jobs, coupled with the drive for higher 'standards' (including a significant level of qualification inflation) has also had negative effects. Quinn et al (2006) suggest that the changed and changing nature of 
the labour market has resulted in a number of challenges which clash with both the cultural and historical position of white working class males. Whereas there once existed an ample supply of industrial jobs that would be available to them on leaving school, a much more uncertain career path awaits current generations of working class school leavers (Henderson 2007). Since the 1980s 'macho working-class masculinity began to take on a dislocated and even slightly desperate character as the infrastructure of traditional industrial working-class life began to collapse' ( $\mathrm{O}^{\prime}$ Donnell and Sharpe 2005: 95). In addition, the fact that women outperform their male counterparts in school and overtake them in the labour market has resulted in further lowering the confidence of working class males as opposed to encouraging them to achieve more highly (Marks 2003).

In a similar vein, Nayak (2003) concludes that in order to fully understand school boy masculinities, it is important to look beyond the school into the various contexts within which such masculinities are formed. Similar to Marks, Nayak advocates the examination of social and cultural structures which impact on the nature of masculinities and the relationships held between young men and family, peers and the labour market within contemporary society.

In his ethnographic investigation of white working class males in Newcastle, Nayak discovered that the male school subculture sought to perpetuate industrial masculinities within a post-industrial society through everyday life activities which were not necessarily labour focused. According to Nayak this was a means of creating some form of stability within a changed and uncertain social climate. This subculture made it difficult for its members to grasp the values of the "new enterprise culture" (Nayak 2003) which encompasses the pursuit of a formal education. Nayak concludes that it is therefore important for schools to take into account the cultural politics of schooling and the individualised institutional situations, whose connections and fractures (neglected at the level of the system) continually produce frictions, disharmonies and contradictions within and among individual biographies' (Nayak 2003: 157).

The underachievement of boys at secondary level has also been linked with a loss of self-esteem. This may begin in primary school when boys fall behind in reading and writing. The decline may continue into secondary 
education and be further compounded by the perceived favouring of girls in GCSE assessments as suggested in the work of Machin and McNally (2005). This may lead to boys escaping into an anti-education culture in order to establish an alternative identity and status. From this viewpoint the education system may be lacking when it comes to enabling all children to maintain sufficient self-esteem levels (Cassen and Kingdon 2007).

Probably the most renowned study concerning working class white boys and education was provided by Willis (1977). Within this study Willis observed and interviewed 12 white working class boys, all connected by an non-academic, counter-school culture. This counter-school culture involved an overt opposition to authority and traditional school processes. In his book Learning to Labour, Willis states that the culture expressed by the group was an attempt to 'weave a tapestry of interest and diversion through the dry institutional text' (Willis 1977: 52). According to Willis, the counter-school culture was produced against a wider backdrop of working class culture in which educational talents are not valued and practice is seen to be more important than theory. Willis suggests that within the sub-culture of these boys, qualifications were viewed with much scepticism. From their perspective, the sacrifice needed for high academic achievement would not yield any worthwhile return; firstly because the qualifications gained were likely to be low anyway and secondly because qualifications were unlikely to be a significant selection criterion for the jobs they were likely to obtain (Willis 1977).

In reality, the relationship between the working class and education has been typically problematic and emotionally charged (Reay 2001). The fact of the matter is, that the educational journeys of working class students and those of middle class students are markedly different. In terms of their views towards education, it is argued by Cohen that for most of the working class, education has remained 'something to get through rather than go into' (cited in Reay 2001: 335). For example, Evans (2006) argues that working class children are disadvantaged by the disparity between the nature of school-based learning and the participation that is required from them within the home. In contrast middle class parents tend to require from their children a similar type of participation to that demanded at school. The working class child is often less prepared to operate within a system that 
expects children to have been prepared at home for formal learning within the school setting.

Additional tension can also be created by the disparity between the demands of school-based formal learning and the external forms of participation that are familiar to working class children. The legitimate, government approved, route to educational success conflicts with other methods of increasing status of which working class children may be proud. These young people may therefore display considerable resistance against an education system that is largely modelled on middle class values. Reay argues that such ideas dominate a British education system in which 'working class education is made to serve middle class interests' (Reay 2001: 334). For Reay, the contemporary education system is one which elevates middle class cultural capital as opposed to that of the working class. With regards to policy, Reay additionally comments that contemporary educational policy ensures that educational failure remains more closely associated with the working class.

Within this section, an attempt has been made to chart and explore some key theoretical perspectives that have been used in an attempt to explain the ways in which the educational experiences of working class white boys serve to shape not only their perceptions and ambitions but also their future life chances. Consideration is given later in the discussion to the power of such forms of discourse in influencing how young people perceive themselves.

\section{Methodological approach}

A case study (Bassey 1999) approach was utilised to carry out the study. The intention from the outset was to capture 'thick description' about the lives of the young people involved through a series of direct conversations. The advantage of such an approach is that it is specifically designed to allow the researcher to explore a single setting, group of people, approach to work, etc. In an effort to capture the voice of participants a structure for engagement had to be devised that would allow the young people concerned to speak freely, openly and confidentially about their experiences. 
To support such an approach the young people involved had to be willing to take part in the project (parental permission was also required).

Those involved in the interview process had all initially been recruited to a school mentoring project (involving one-to-one support with an adult mentor) aimed at improving educational performance over the period of an academic year. Two specific criteria had to be met by students in order for them to be involved in this mentoring project. Firstly, they had to be underachieving within at least the core subject areas (English, maths and science) and secondly that students had to be male and from a white working class background. To ensure that the most suitable students were chosen the selection process was carried out in three stages. Firstly, the deputy head at the target school pinpointed a number of students that might possibly fulfil the criteria. From the original list of students, the project team created a shortlist using random sampling techniques (Cohen, Manion and Morrison 2005). Selections were based on the differences between students predicted and attained test scores in English, science and maths. It was from this short list that the project team then selected a final list of 10 potential mentees and also six reserves, in case selected pupils declined to participate, or decided to leave the project soon after it had started.

As part of the final selection process the project team also considered students' attendance percentages and behavioural records. Behaviour records sheets displayed: events of misbehaviour, the nature of the behaviour, the date of the event and also the subject lesson in which the behaviour took place. It was felt that the use of such data would serve to highlight those particular young people who might be experiencing the highest levels of difficulty within school in terms of behaviour, subject performance, attitudes to school etc. These were considered important factors in respect of participation in the year-long mentoring project.

In order for students to be involved in the mentoring project, consent had to be gained from both the selected individuals and their parents. In the case of the 10 selected students each had a brief meeting with the deputy head of the school who had been in close contact with the research team and therefore had considerable knowledge of the project. Within this meeting the deputy head ensured that each student had an adequate understanding of why they had been selected to take part in the project with regards to 
their academic underachievement and also ensured that students understood the concept of mentoring. Students were then asked if they would like to receive additional support from a mentor during the following year. Within these meetings each of the selected students gave their verbal consent to be involved in the project.

Once the consent of the young people had been gained, letters were then sent home to their parents to gain parental permission. In this letter parents were given a brief overview of the project and its aims and were invited to contact the deputy head if they needed any additional information. Parents were also required to complete a short form to confirm they were happy for their child to be involved in the project. These forms were then returned to the deputy head. The young people were made aware of the fact that they would be interviewed about their attitudes to education, work, and future career prospects. A semi-structured interview (Cohen, Manion and Morrison 2005) approach was used to support this work. All of the students were interviewed at the beginning and end of the programme these were termed 'initial' and 'exit' interviews. Students were guaranteed complete anonymity and confidentiality in relation to any issues raised during the course of the interviews. Ethical approval was granted by the sponsoring university for the research work to be carried out.

\section{Perceptions of the participants}

During the course of the interviews a number of common issues were raised by all of the participants in exploring their views of education and work. Those involved consistently linked three aspects of their day-to-day lives as being highly influential not only in shaping their perceptions, but also as instrumental in ultimately determining their future life chances. The themes of school environment, community and family networks and ideas of care were discussed at length as the students reflected on both the causes of their perceived underachievement and the way educational experiences position them personally, socially and economically. Each of the themes is explored in some depth below. 
Students were encouraged to try and define the characteristics of the school environment. In describing that environment some of the characteristics employed appeared, on the surface at least, to be contradictory. For example, it was not unusual to find emphasis placed on the oppressive nature of learning regimes that required conformity in terms of following the demands of particular curricular-driven schemes of work, the inflexibility of teaching approaches and the over-use of sanctions to enforce discipline. At the same time, students commented on the personal security that attendance at school gave them, the way the school offered them a sense of self-identity and belonging, and the potential that school held as a way of improving later life chances. Contradiction and ambivalence towards school, and specific aspects of it, was reflected in a number of interview conversations. This is considered below through an examination of interview data that dealt with general perceptions of education.

The young people involved clearly recognised the benefits of academic success for their futures both in terms of employment and quality of life. This perspective was most commonly demonstrated through comments pertaining to the correlation between achieving good academic grades and gaining employment, or what was construed to be a 'decent job'. Two extracts that illustrate this perspective are used here. Within the second extract in particular, the acquiring of material goods is directly related to academic study. Here, material gain is seen to be the expected reward of academic pursuits. These mentees clearly subscribe to a perspective that good grades translate into good jobs and good income levels:

...I want to get a decent job I am not going to be able to do that if there are some things aren't going well for me like maths, if I don't do well in that then I will probably try and do it again in college.

It is worthwhile because it is going to reflect on your future, more study and the more you study the more you .... and you get a better job, a better house and a lot of money so I won't mind that.

Students also spoke about good grades or educational success being instrumental in enabling them to proceed to college and pursue the further education course of their choice. 
Partly, like it [mentoring] reminds you of why what it is going to be like what you have got to do how to get on with like the work and that, it tells you, it reminds you that you need all these grades to get in to college and go on to do what I want to do.

Yet, despite holding positive perspectives about the value of education, the young people concerned talked openly about their personal 'limitations' as well as how they felt the education system 'failed' them. Some cited an aversion to education and academic work as being a major problem that they had to confront on a daily basis. For example one of the students said:

I'd like to get higher in my GCSEs and stuff but like, I don't want to do the work.

Now, it would be easy to declare a student like this to be essentially lazy. However, a more detailed exploration of such a perspective reveals the power of 'problematizing' discourse in influencing matters of self-definition and ultimately self-esteem. For example, one young person commented:

Yep! I'll admit I'm a bit idle but how'd that happen? Blame myself to some point but when you've spent most of your school life being told you're next to useless then you give up. You say, what's the point stuff like that. Get it?

A degree of conflict was also apparent when it came to reviewing what the students saw as the characteristics of hard-working pupils. In the extract below it is clear that the student directly relates consistent working and concentration to certain innate characteristics, specific to only certain people. The young person seems to distance himself from the particular individuals that he is referring to, suggesting that whilst he values educational success he perceives it as something that comes more naturally to some than others.

Everyone is different ain't it, some people are built with that thing that brain where they can work throughout the whole day. They get bored and they don't like it but they know they have got to do it and their brain says yeh you got to do it so they do all the work.

From many of the students' responses it is clear that they value education and realise the potential benefits of educational success in relation to their future lives. This is a very different outlook on education compared to that of the lads in Willis's (1977) study who were deeply sceptical about educational talent and qualifications since they were unlikely to influence 
job choice. The students in this study seemed to generally hold an idealistic meritocratic perspective, where educational advancement and achievement inevitably leads to worthwhile rewards such as a 'decent job', and other material commodities. In this sense, the students valuing of education seems to be instrumentally driven. There is however some element of conflict in that whilst there is a valuing of education there is also some degree of reluctance to carry out the work and participation needed in order to achieve educational success. There is also a degree of separating out those 'who can' and those 'who can' $t$ ' with such a distinction being constructed around presumed 'brain power'.

Despite the kind of perspectives described above the vast majority of the students involved in the study had not 'given up' on school work. They were able to articulate the difficulties and dilemmas they faced when it came to studying - it was clear from the research data available that they understood the nature of the specific barriers to learning that confronted them on a daily basis. The issue of distraction emerged as a predominant factor for most of the group. A number of the young people identified the fact that friendship associations can act as a key barrier to learning. The students reported that they were frequently distracted from their work by friends talking and 'messing around'. Below, a practical example, described by one of the students, is presented for consideration:

... like it is easy to like, to get involved, like if it's just two people in the class messing around and say they are throwing something like if they throw it towards you and it hits you and then you throw it back then you're already involved cause they'll keep doing it now, and then it gets worse and worse, you get caught, the teacher moans, you have an argument with the teacher maybe get kicked out so you don't get the work done, then it would all quieten down.

Umm sometimes friends, sometimes if I am in a working state then they will start messing about, I dunno, I can't fight it off I can't not mess around, I can't stop messing around with them, I just can't.

Although the young people enjoyed 'fooling around' with their friends, they also realised that within the classroom context this type of interaction hindered them and jeopardised their chances of gaining academic success. In this sense, the above extracts demonstrate a significant area of personal and collective conflict for the young people concerned. They identified the 
power of dominant peer culture as being particularly influential. Yet at the same time they linked that behaviour to how they saw the value of the school and their treatment within it:

It's more than choice. It's like saying this place they don't really expect much from us. So, you pick up on that and then it's like it's a game. We don't do, we mess about, we know it's wrong even but that doesn't stop you. Dunno, what do they care .... Some of the teachers just want us out of the lesson. So, 'playing up' is more fun. We know they want us off the premises and then the place would be quiet .... And half empty!

Through the research process it became evident that the school climate, in terms of the context within which learning takes place, is both complex and complicated. The value of education in relation to its ability to improve the life chances of those involved was not disputed by the students. Yet notions of exclusion and inequality permeated many of the interviews. The young people involved largely saw themselves as outsiders; those that came into the school but were unable, or weren't expected, to experience its full benefits. School-based peer relations were important but largely involved forming relationships 'with kids like yourself'. Learning was viewed instrumentally in the sense that it had the potential to open the door to a range of future careers. And yet at the same time the young men concerned were asked to make sense of a changing world against the backdrop of a traditional white working class community life where job opportunities (and particularly semi-skilled and unskilled jobs) had all but disappeared. This issue is explored further in the next section.

\section{Community and family networks}

All of the working class white boys involved in the study were drawn from the same local community. It would not be unfair to say that the community was, and continues to be, in a state of considerable economic decline. The disappearance of traditional jobs, which included car construction and chocolate manufacture, has brought with it a physical degeneration in the infrastructure of the community, loss of earnings and a withering away of a particular kind of 'cultural capital': 
'... forged through notions of the patriarchal "breadwinner," physical "hardness" and a strict sexual division of labour that split the public "masculinities" world of work from the domestic realm of unpaid work' (Nayak 2009: 151).

While the young people talked about their parents 'hanging on' to these notions and values as a way of trying to create ongoing meaning (in terms of their day-to-day existence) at a time of considerable social and economic flux, the young people were left to negotiate a very different education and employment terrain. For example, one young man described the situation thus:

We come from a place where jobs have gone, rubbish pay is what you know you will get and if you can't get that then it's schemes or college courses... My mates have been on loads of schemes waste of time.

In reviewing the quote, connections can be made between such a perspective and Chatterton and Hollands (2003) view of a 'post-Fordist labour market' marked out by low paid employment, successive job 'creation' schemes, periods of unemployment, and short term contracts. Those involved in the research appeared to accept the inevitability of such an existence and all that went with it. As a result, the importance of peerbased relationship bonds constructed at the level of the community became all the more valuable. It is also important to note that such relationships transferred into the school situation and to some extent influenced the behaviour of the individuals concerned. Again, one young person summarised the situation succinctly:

Teachers don't get it, you can't grass [tell on your friends], be like a swot [appear academic] ain't easy.... You stick with your mates inside and outside school 'cos they'll back you and teachers don't. You fight for them [this included physical violence] and they'll do it for you.

There can be no doubt, that peers and parents are extremely influential in shaping perceptions of the value of education and its relationship to future careers and work. Yet at the same, the young men involved in the research made clear connections between how they were viewed by the school and the cultural 'reputation' of the area where they lived. The power of such connections features strongly in the work of Nieto (1999) who argues that 'problematizing' discourse of various kinds is used to justify the 
treatment of particularly groups of young people - in this case white working class boys. Such discourse variously employs the ideas of lack of motivation, genetic inferiority, differing cultural values and a lack of personal direction as key characteristics of underachievement and lack of success; a 'cultural deficit' is constructed by policy makers and practitioners alike, based on an inability on the part of working class young people to gain 'middle class skills with which to navigate a different life, especially within school' (Smyth, Down and McInerney 2010: 20).

What emerges from the research is the power of 'deficit identities' in shaping the perceptions of this group of students. The notion of 'deficit' is largely constructed from a position that 'blames' the young people concerned for their inability to make educational or career progress. One young person insightfully commented:

School blames us, the place where we live, your mates, your parents, your brothers and sisters... really anyone but themselves [school]. That can't be right....

\section{The idea of caring}

In opening this section use is made of a quote from Noddings (2005: 17) to illustrate the importance of caring, or in the case of the young men involved in this study a perceived lack of it within school, in directly influencing perceptions as to the value of education. For Noddings argues that:

The desire to be cared for is almost certainly a universal human characteristic. Not everyone wants to be cuddled or fussed over. But everyone wants to be received, to elicit a response that is congruent with an underlying need or desire.

What is particularly interesting to observe, in relation to this research, is how the concept of caring is defined and demonstrated within the everyday lives of young people concerned. The concept of caring can be seen to work at a number of different levels and in doing so fulfills a number of different purposes. A sense of 'tough caring' was seen to exist in what Noddings might describe as 'equal relations' (Noddings 2005: 92). Overlaid by masculine preoccupations of strength and collective 'muscle', the young 
men talked about 'watching your mate's back', 'looking out for each other' and 'respecting' as crucial elements of caring relationships with their peers. Parents were seen to care, sometimes in 'tough' ways through, for example, physical punishment, chastisement and 'grounding' and in 'softer' ways by 'talking things over', 'being a good listener' and 'sticking by you'. Yet it was in relationships with teachers that a real sense of a lack of caring emerged from the perspectives of the young people. The two quotes below capture the sense of loss, isolation and exclusion felt by a general lack of caring within schools:

It's hard to face up to the fact that nobody wants you. Sounds a bit pathetic but you know the kids they like and them they don't... Disrespected and left out almost all the time.

Sit in a class and see what goes on. You'd see how we get treated different... nobody has a laugh with you or joke or even smiles.

What appeared to be lacking for almost all of the participants was any kind of empathetic connection with those teachers they engaged with on a daily basis. This lack of engagement seems to exist at two levels - the students appeared to demonstrate little in the way of understanding, or caring, for the difficulties that teachers faced in their work and the teachers it was claimed 'cared little' about them. How much further removed could such a position be from the importance attached by Cooper et al (2000: 186) for the need to create 'moments of genuine communication and empathy, when meanings are shared across the student teacher divide, when teachers and students reach mutual understandings of each other's positions'?

\section{Concluding reflections}

In deciding on a title for this article, it was important to capture a sense of the fact that the young people's voices used within it speak from 'the margins'. Such a sense of marginalisation is the direct product of both how they view the value and worth of education in their lives, and the way that value position reinforces many of their feelings about their own self-worth. Their future, from their perception at least, is marked out - in a sense the future is preordained. Their ambitions are low. A world of work beckons that is uncertain and to a significant degree unstable, reflecting as it does 
economic and social changes for both themselves and their families. The young people understand the meritocratic lure of education. Yet at the same time, they see it as an alien terrain in the sense that the promises made by teachers and those that make education policy are meant for someone else. Like Willis's (1997) 'lads' they seem to make a calculated choice in terms of education 'not being worth the effort', when the uncertain rewards they are presented with only serve to reinforce their meagre expectations.

Best (2005) captures a key element of the education process that seems to be significantly missing for all of the young men involved in this study. The relationships that these working class white boys have with those who are directly involved in their education appear to be of a very poor quality. As Best (2005) argues:

What makes a lasting impression on us are the attitudes of our teachers towards us, embodied in the quality of the relationships they form with us. Yet the contemporary pre-occupation with the testing of a fragmented curriculum in a competitive context has the effect of individualizing the learning experience. The outcome is all; the quality of the relationships between individuals is hardly acknowledged.

At the same time Best points to the failure of the curriculum, with its preoccupation with testing and competition, as significantly adding to the difficulties experienced by this group of boys. Smyth, Down and McInerney (2010) return to the thoughts of Dewey (1959) and the failure of schools to value and positively 'utilize' the community experiences of students in constructing an argument for radical curriculum reform. In essence, the case is made that unless a genuine 'dialogic relationship' is created that values and respects the individual and the community they come from, then 'the dominant hegemonic curriculum' will continue to work against 'the interests of minority students' (Smyth, Down and McInerney 2010: 78).

The challenge in reviewing the evidence presented in this paper for educationalists and policy makers alike is to carefully consider the changes that will need to put into place to positively meet the needs of working class white boys. Their educational failure should greatly concern all sections of UK society. Blaming this group of boys for their individual and collective failure, and 'problematizing' their lives and the communities they come from, does little in terms of changing thinking and educational strategy. The 
social and economic costs to society of further alienating this group of young people are significant. Relationship building, curriculum reform and the creation of new pedagogical approaches need, as Noddings (2005: 150) advocates 'to begin with the purposes, interests, and capacities of students'.

\section{References:}

Bassey, Michael. 1999. Case Study Research in Educational Settings. Buckingham: Open University Press.

Cassen, Robert and Geeta Kindon. 2007. Tackling Low Achievement. York: Joseph Rowntree Foundation.

Cohen, Louis, Lawrence Manion and Keith Morrison. 2005. Research Methods in Education. London: RoutledgeFalmer.

Chatterton, Paul and Robert Hollands. 2001. Changing our 'toon': Youth nightlife and urban change in Newcastle. Newcastle upon Tyne: University of Newcastle.

Cooper, Paul, Mary Jane Drummond, Susan Hart, Jane Lovey and Colleen McLaughlin. 2000. Positive Alternatives to Exclusion. London: RoutledgeFalmer.

Clayden, Jasmine and Mike Stein. 2005. Mentoring for Young People Leaving Care. 'Someone for me'. York: Joseph Rowntree Foundation.

Evans, Gillian. 2006. Educational Failure and Working Class White Children in Britain. London: Palgrave Macmillan.

France, Alan. 2004. Young People. In Doing Research with Children and Young People, eds. Sandy Fraser; Vicky Lewis; Sharon Ding; Mary Kellett and Chris Robinson, 175-190. London: Sage Publications.

Francis, Becky. 1999. Lads, Lassies and (New) Labour: 14-16-year-old Student Responses to the 'Laddish Behaviour and Boys' Underachievement' Debate. British Journal of Sociology of Education 20 (3): 335-371.

Griffin, Christine. 1993. Representations of Youth: the Study of Youth and Adolescence in Britain and America. Cambridge: Polity Press.

Henderson, Sheila. 2007. Neighbourhood. In Youth in context: frameworks, settings and encounters, ed. Martin Robb, 123-154. London: Sage Publications.

Lindsay, Geoff and Daniel Muijs. 2006. Challenging Underachievement in Boys. Educational Research 48 (3): 313-332.

McKnight, Andrew N. 2006. Defining other people's poverty: Ruby Payne's bourgeois essentializing of class struggle. Paper presented at the annual meeting of the American Educational Studies Association, November 4, Spokane, USA. 
Marks, Andrew. 2003. Welcome to the New Ambivalence: Reflections on the Historical and Current Cultural Antagonism Between the Working Class Male and Higher Education. British Journal of Sociology of Education 24 (1): 83-93.

Mills, Martin, Becky Francis and Christine Skelton. 2009. Gender Policies in Australia and the United Kingdom: The Construction of "New" Boys and Girls. In The Problem with Boys' Education Beyond the Backlash, eds. Wayne Martino; Michael Kehler and Marcus B. Weaver-Hightower, 36-55. Abingdon: Routledge.

Nayak, Anoop. 2003. Boyz to Men: Masculinities, Schooling and Labour Transitions in De-industrial Times. Educational Review 55 (2): 147-159.

Nayak, Anoop. 2009. The Beer and the Boyz: Masculine Traditions in a PostIndustrial Economy. In The Problem with Boys' Education Beyond the Backlash, eds. Wayne Martino; Michael Kehler and Marcus B. Weaver-Hightower, 149-168. Abingdon: Routledge.

Nieto, Sonia. 1999. The Light in Their Eyes: Creating Multicultural Learning Communities. New York: Teachers College Press.

Noddings, Nel. 2005. The Challenge to Care in Schools: An alternative Approach to Education Second Edition. New York: Teachers College Press.

O'Donnell, Mike and Sue Sharpe. 2005. The Social Construction of Youthful Masculinities: Peer Group Sub-cultures. In The RoutledgeFalmer Reader in the Sociology of Education, ed. Stephen J. Ball, 89-127. London: RoutledgeFalmer.

Quinn, Jocey, Liz Thomas, Kim Slack, Lorraine Casey, Wayne Thexton and John Noble. 2006. Lifting the Hood: Learning and Young, White Provincial Working-Class Masculinities. British Educational Research Journal 32 (5): 735-750.

Reay, Diane. 2001. Finding or Loosing Yourself?: Working-class Relationships to Education. Journal of Education Policy 16 (4): 333-346.

Smyth, John, Barry Down and Peter McInerney. 2010. Hanging in with Kids in Tough Times: Engagement in Contexts of Educational Disadvantage in the Relational School. New York: Peter Lang.

Whitty, Geoff. 2001. Education, Social Class and Social Exclusion. Journal of Educational Policy 16 (4): 287-295.

Willis, Paul E. 1977. Learning to Labour: How Working Class Kids Get Working Class Jobs. London: Saxon House.

Younger, Mike and Molly Warrington. 2005. Raising Boys' Achievement in Secondary School. Maidenhead: Open University Press. 